\title{
Long term non-invasive ventilation in the community for patients with musculoskeletal disorders: 46 year experience and review
}

\author{
Ahmet Baydur, Elaine Layne, Hilkat Aral, Nageswari Krishnareddy, Ruth Topacio, \\ Glynnis Frederick, Walbert Bodden*
}

\begin{abstract}
Background-A study was undertaken to assess the long term physiological and clinical outcome in 79 patients with musculoskeletal disorders (73 neuromuscular, six of the chest wall) who received non-invasive ventilation for chronic respiratory failure over a period of 46 years. Methods-Vital capacity (VC) and carbon dioxide tension $\left(\mathrm{PCO}_{2}\right)$ before and after initiation of ventilation, type and duration of ventilatory assistance, the need for tracheostomy, and mortality were retrospectively studied in 48 patients who were managed with mouth/nasal intermittent positive pressure ventilation (M/NIPPV) and 31 who received body ventilation. The two largest groups analysed were 45 patients with poliomyelitis and 15 with Duchenne's muscular dystrophy. Twenty five patients with poliomyelitis received body ventilation (for a mean of 290 months) and 20 were supported by M/NIPPV (mean 38 months). All 15 patients with Duchenne's muscular dystrophy were ventilated by NIPPV (mean 22 months).
\end{abstract}

Results-Fourteen patients with poliomyelitis on body ventilation $(56 \%)$ but only one on M/NIPPV, and 10 of 15 patients (67\%) with Duchenne's muscular dystrophy eventually received tracheostomies for ventilatory support. Five patients with other neuromuscular disorders required tracheostomies. Twenty of 29 tracheostomies $(69 \%)$ were provided because of progressive disease and hypercarbia which could not be controlled by non-invasive ventilation; the remaining nine were placed because of bulbar dysfunction and aspiration related complications. Nine of 10 deaths occurred in patients on body ventilation (six with poliomyelitis), although the causes of death were varied and not necessarily related to respiratory complications. A proportionately greater number of patients on M/NIPPV (67\%) reported positive outcomes (improved sense of wellbeing and independence) than did those on body ventilation $(29 \%$, $\mathrm{p}<0.01)$. However, other than tracheostomies and deaths, negative outcomes in the form of machine/interface discomfort and self-discontinuation of ventilation also occurred at a rate 2.3 times higher than in the group who received body ventilation. None of the six patients with chest wall disorders (all on M/NIPPV) required tracheostomy or died. Hospital admission rates increased nearly eightfold in patients receiving body ventilation (all poliomyelitis patients) compared with before ventilation $(p<0.01)$ while in those supported by M/NIPPV they were reduced by $36 \%$.

Conclusions-Non-invasive ventilation (NIV) in the community over prolonged periods is a feasible although variably tolerated form of management in patients with neuromuscular disorders. While patients who received body ventilation were followed the longest (mean 24 years), the need for tracheostomy and deaths occurred more often in this group (most commonly in the poliomyelitis patients). Despite a number of discomforts associated with M/NIPPV, a larger proportion of patients experienced improved wellbeing, independence, and ability to perform daily activities.

(Thorax 2000;55:4-11)

Keywords: chronic respiratory failure; chronic neuromuscular disease; poliomyelitis; Duchenne's muscular dystrophy; non-invasive ventilation

Since the end of the poliomyelitis epidemic in the 1950s negative and positive pressure ventilators have evolved to become more compact and versatile so that they are now used in various neuromuscular, chest wall, airways and pulmonary parenchymal disorders. ${ }^{1}$ We present our experience with long term noninvasive ventilation in terms of physiological change, survival, and complications over a period of more than 40 years, with particular reference to outcomes in patients with neuromuscular and chest wall disorders. The main objective of this retrospective study was to assess physiological changes, length of use of 
Table 1 Diagnosis of patients studied

\begin{tabular}{ll}
\hline Diagnosis & No. \\
\hline Total & 79 \\
Neuromuscular & 45 \\
$\quad$ Poliomyelitis & 15 \\
Duchenne's muscular dystrophy & 4 \\
Other myopathy & 2 \\
Motor neurone disease & 2 \\
$\quad$ Amyotrophic lateral sclerosis & 3 \\
$\quad$ Spinal muscular atrophy & 2 \\
Pultiple sclerosis & \\
Chest wall disorders & 5 \\
$\quad$ Kyphoscoliosis & 1 \\
Thoracoplasty for tuberculosis & \\
\hline
\end{tabular}

non-invasive ventilation, need for change in type of ventilation, and eventual patient outcome.

\section{Methods}

Rancho Los Amigos Medical Center is a teaching rehabilitation facility of the University of Southern California that has cared for patients with neuromuscular and chest wall disorders with respiratory complications since the early 1940s. Between July 1949 and July 1995 approximately 560 patients with neuromuscular and chest wall disorders were admitted for respiratory impairment or failure and managed with non-invasive ventilation. Of these patients, 500 had poliomyelitis with bulbar and respiratory involvement; their early outcomes were reviewed by Affeldt et $a l^{2}$ in 1957. Most of these 500 patients $(73 \%)$ were weaned off ventilation within two years; 70 $(14 \%)$ died and $66(13 \%)$ were still ventilator dependent after two years. Another 60 patients in the present study had other neuromuscular and chest wall disorders, the most common of which was Duchenne's muscular dystrophy. From this pool of 126 patients ( 60 plus 66 of Affeldt's remaining ventilator dependent poliomyelitis patients), the records of 79 individuals (40 men) placed on long term non-invasive ventilation (table 1) were assessed on the basis of (1) their discharge into and continued living in the community, and (2) availability of vital capacity (VC) and carbon dioxide tension
$\left(\mathrm{PCO}_{2}\right)$ data before and after starting ventilation as outpatients in the community. Many of the 126 patients did not have complete records and had to be dropped from the analysis. A follow up period of at least one month was determined on the basis of classifying the patient as ventilator dependent if they were unweanable after four weeks. ${ }^{3}$ Criteria for initiation of noninvasive ventilation were ${ }^{4}$ : (1) acute respiratory failure because of rapid deterioration of neuromuscular function; (2) presentation of progressive dyspnoea/orthopnoea, frequent waking, cor pulmonale and headache; (3) elective initiation of ventilation when $\mathrm{PCO}_{2}$ increased to $45 \mathrm{~mm} \mathrm{Hg}$ even in relatively asymptomatic patients, particularly in those with a background of neuromuscular disease known to be progressive. As can be seen in table 1, 45 (57\%) of the patients had poliomyelitis, 16 of whom had received body ventilation since the onset of their illness (table 2). These 16 were survivors from the original group of 500 poliomyelitis patients with acute respiratory complications described by Affeldt et al (criterion 1). The remaining nine poliomyelitis patients on body ventilation required ventilation because of late onset respiratory sequelae and were admitted primarily on the basis of criterion 2 . The second largest group of patients consisted of 15 individuals (19\%) with Duchenne's muscular dystrophy, 12 of whom were admitted based on criterion 2, and three based on criterion 3. All four patients with motor neurone disease were admitted for criterion 2 as were the six patients with chest wall disorders (five with kyphoscoliosis and one with post-tuberculosis lobectomy and thoracoplasty).

Detailed diagnostic anthropometric and physiological information for the patients is listed in tables 2 and 3. Predicted values of vital capacity were based on those of Morris et al. ${ }^{5}$ In patients with kyphoscoliosis predicted values were obtained on the basis of arm span. ${ }^{6}$ Ventilation was assessed in all patients during the daytime by arterial $\mathrm{PCO}_{2}$ or the rebreathe $\mathrm{PCO}_{2}$ method of Hackney et al. ${ }^{7}$ Follow up daytime $\mathrm{FVC}$ and $\mathrm{PCO}_{2}$ were measured for the most

Table 2 Characteristics of 31 patients on negative pressure ventilation (shell or tank)

\begin{tabular}{|c|c|c|c|c|c|}
\hline Diagnosis & Poliomyelitis & $\begin{array}{l}\text { Non-Duchenne's } \\
\text { myopathies }\end{array}$ & $\begin{array}{l}\text { Motor neurone } \\
\text { disease }\end{array}$ & $\begin{array}{l}\text { Diaphragmatic } \\
\text { paralysis }\end{array}$ & Multiple sclerosis \\
\hline No. of patients $(\mathrm{M} / \mathrm{F})$ & $25(13 / 12)$ & $2(1 / 1)$ & $2(1 / 1)$ & $1(0 / 1)$ & $1(0 / 1)$ \\
\hline Age when ventilator started (years) & $26.0(10.2)$ & $18.5(0.71)$ & $62.0(12.7)$ & 29 & 47 \\
\hline Height $(\mathrm{cm})$ & $169.1(11.5)$ & $156.2(34.1)$ & $161.3(1.8)$ & 160 & 154.9 \\
\hline Weight $(\mathrm{kg})$ & $57.7(12.2)$ & $33.2(1.3)$ & $44.8(8.7)$ & 56.4 & 57.7 \\
\hline \multicolumn{6}{|l|}{ FVC (ml; \% predicted) } \\
\hline $\mathrm{a}$ & $800(383) ; 20(8) \%$ & $625(460) ; 19(9) \%$ & $950(50) ; 34(3) \%$ & $1300 ; 44 \%$ & $1300 ; 63 \%$ \\
\hline $\mathrm{b}$ & $730(336) ; 19(7) \%$ & $550(495) ; 14(14) \%$ & $300(20) ; 9(3) \%$ & $1200 ; 38 \%$ & $1270 ; 57 \%$ \\
\hline \multicolumn{6}{|l|}{$\mathrm{PCO}_{2}(\mathrm{~mm} \mathrm{Hg})$} \\
\hline a & $46.1(10.0) \dagger$ & $51.5(0.71)$ & $50.5(6.5)$ & 62 & 43 \\
\hline $\mathrm{b}$ & $46.5(14.5)$ & $68.5(14.8)$ & $46.5(9.2)$ & 48 & 34 \\
\hline Time on non-invasive ventilation (months) & $290(148)+\dagger$ & $46(31)$ & $174(229)$ & 46 & 396 \\
\hline \multicolumn{6}{|l|}{ Gain or decline in FVC } \\
\hline $\mathrm{ml} / \mathrm{year}$ & $-4.8(13.8) \ddagger$ & $-81.3(97.2)$ & $-25.0(0)$ & -26.1 & -7.0 \\
\hline$\%$ predicted $/$ year & $-0.09(0.31)$ & $-2.0(1.4)$ & $-0.8(0)$ & -1.6 & -1.4 \\
\hline No. of patients eventually needing trachostomy & $14 \sqrt{\Omega}$ & 2 & 1 & 0 & 0 \\
\hline No. of deaths & $6^{\star}$ & 0 & 2 & 0 & 1 \\
\hline
\end{tabular}

Values are mean (SD) unless otherwise stated.

$\mathrm{a}=$ before ventilation; $\mathrm{b}=$ near end of period on ventilation; $\mathrm{FVC}=$ forced vital capacity; $\mathrm{PCO}_{2}=$ carbon dioxide tension.

†Significantly different from polio-M/NIPPV patients (table 3), $\mathrm{p}<0.05$ (Wilcoxon rank sum test).

+†Significantly different from polio-M/NIPPV patients (table 3), $\mathrm{p}<0.01$ (Wilcoxon rank sum test)

$\ddagger$ Significantly different from polio-M/NIPPV patients (table 3 ), $\mathrm{p}<0.01$ (Wilcoxon rank sum test).

SSignificantly different from polio-M/NIPPV patients (table 3), $p<0.01$ (Wilcoxon rank sum test).

${ }^{\star}$ Significantly different from polio-M/NIPPV patients (table 3), $\mathrm{p}<0.01$ (Wilcoxon rank sum test). 
Table 3 Characteristics of 48 patients on mouth/nasal intermittent positive pressure ventilation (M/NIPPV)

\begin{tabular}{|c|c|c|c|c|c|c|c|c|}
\hline Diagnosis & Poliomyelitis & $\begin{array}{l}\text { Duchenne's } \\
\text { muscular } \\
\text { dystrophy }\end{array}$ & $\begin{array}{l}\text { Other } \\
\text { myopathies }\end{array}$ & $\begin{array}{l}\text { Motor neurone } \\
\text { disease }\end{array}$ & $\begin{array}{l}\text { Peripheral } \\
\text { neuropathy }\end{array}$ & Multiple sclerosis & Kyphoscoliosis & $\begin{array}{l}\text { S/P lobectomy } \\
\text { thoracoplasty } \\
\text { for TB }\end{array}$ \\
\hline No. of patients $(\mathrm{M} / \mathrm{F})$ & $20(6 / 14)$ & $15(15 / 0)$ & $2(1 / 1)$ & $2(0 / 2)$ & $1(1 / 0)$ & $2(1 / 1)$ & $5(1 / 4)$ & $1(0 / 1)$ \\
\hline Age when treatment started & $48.1(12.6)$ & $20.3(5.0)$ & $22(15.6)$ & $43.5(19.1)$ & 41 & $46.5(3.5)$ & $44.8(9.0)$ & 48 \\
\hline Height $(\mathrm{cm})$ & $166.8(11.7)$ & $172.7(11.6)$ & $165.1(10.8)$ & $152.4(3.6)$ & 182.9 & $160(0)$ & $158.0(16.0)$ & 165.1 \\
\hline Weight $(\mathrm{kg})$ & $60.6(14.9)$ & $48.0(15.1)$ & $32.5(8.7)$ & $55.7(14.5)$ & 50.5 & $95.9(39.2)$ & $40.3(10.7)$ & 63.2 \\
\hline \multicolumn{9}{|l|}{ FVC $(\mathrm{ml} ; \%$ predicted $)$} \\
\hline a & $\begin{array}{l}1134(417) \\
34(12) \%\end{array}$ & $\begin{array}{l}600(219) \\
14(5) \%\end{array}$ & $\begin{array}{l}775(106) \\
18(7) \%\end{array}$ & $\begin{array}{l}613(159) \\
25(12) \%\end{array}$ & $\begin{array}{l}1100 \\
22 \%\end{array}$ & $\begin{array}{l}1150(71) \\
38(1) \%\end{array}$ & $\begin{array}{l}690(143.2) \\
20(3) \%\end{array}$ & $1200 ; 41 \%$ \\
\hline $\mathrm{b}$ & $\begin{array}{l}1219(417) \\
37(14) \%\end{array}$ & $\begin{array}{l}533(379) \\
11(7) \%\end{array}$ & $\begin{array}{l}600(141) ; \\
13(3) \%\end{array}$ & $\begin{array}{l}850(212) \\
34(17) \%\end{array}$ & $800 ; 16 \%$ & $\begin{array}{l}1480(962) \\
47(30) \%\end{array}$ & $\begin{array}{l}690(167.3) \\
20(5) \%\end{array}$ & $1100 ; 33 \%$ \\
\hline \multicolumn{9}{|l|}{$\mathrm{PCO}_{2}(\mathrm{~mm} \mathrm{Hg})$} \\
\hline $\mathrm{a}$ & $51.7(15.2)$ & $49.7(7.5)$ & $48.0(5.7)$ & $54.0(8.5)$ & 38 & $57.5(40.3)$ & $49.2(7.2)$ & 50 \\
\hline $\mathrm{b}$ & $45.1(10.4) \dagger$ & $46.7(8.5)$ & $47.0(9.9)$ & $30.5(3.5)$ & 40 & $54.0(14.1)$ & $52.2(12.4)$ & 36 \\
\hline $\begin{array}{l}\text { Time on non-invasive ventilation } \\
\text { (months) }\end{array}$ & $38(32)$ & $22(22)$ & $41(24)$ & $58(57)$ & 5 & $17(10)$ & $30(21)$ & 32 \\
\hline \multicolumn{9}{|l|}{ Gain or decline in FVC } \\
\hline $\mathrm{ml} /$ year & $90(225)$ & $-60(244)$ & $-66(49)$ & $104(112)$ & -720 & $501(921)$ & $-18(117)$ & -38 \\
\hline$\%$ predicted/year & $3.6(8.2)$ & $-2.3(5.9)$ & $-1.3(0.5)$ & $4.7(5.6)$ & -14.4 & $14.5(29.0)$ & $-0.36(3.1)$ & -3.0 \\
\hline $\begin{array}{l}\text { No. of patients eventually needing } \\
\text { tracheostomy }\end{array}$ & 1 & 10 & 1 & 0 & 0 & 0 & 0 & 0 \\
\hline No. of deaths & 0 & 1 & 0 & 1 & 0 & 0 & 0 & 0 \\
\hline
\end{tabular}

Values are mean (SD) unless otherwise stated.

$\mathrm{a}=$ before ventilation; $\mathrm{b}=$ near end of period on ventilation; $\mathrm{FVC}=$ forced vital capacity; $\mathrm{TB}=$ tuberculosis; $\mathrm{PCO}_{2}=$ carbon dioxide tension.

†Significantly different from pre-ventilation $\mathrm{PCO}_{2}, \mathrm{p}<0.01$ (paired $t$ test).

recent period during which the patient was receiving non-invasive ventilation.

Body ventilation was provided with a tank respirator or cuirass (shell) type device driven by a negative pressure cycled machine. Mouth or nasal intermittent positive pressure ventilation (M/NIPPV) was provided by portable pressure cycled or volume cycled ventilators for a minimum of eight hours at night and for 2-8 hours during the day. Thirteen poliomyelitis survivors also used a variety of oral and/or nasal interfaces for positive pressure ventilation during the day to supplement nocturnal use of a cuirass or tank respirator. Three used a lip seal with their MIPPV to sleep with at night. All other neuromuscular patients on NIPPV used a commercially available face mask (Lifecare, Lafayette, Colorado or Respironics, Murrysville, Pennsylvania, USA). Four poliomyelitis patients who used cuirasses at night used an intermittent abdominal pressure ventilator (IAPV, pneumobelt) while three used rocking beds for daytime ventilator support. All had less than one hour of ventilator free breathing ability. Nasal/mouth interfaces were adjusted to optimise comfort and a good seal. Exsufflation-insufflation devices were provided for patients with virtually no ability to cough and/or bulbar impairment which led to accumulation of secretions that could not be cleared by manual coughing techniques.

DEFINITION OF END POINTS

To assess the efficacy of both negative and positive pressure ventilation, primary end points were defined as death or the need for a tracheostomy while receiving either modality. Additional end points were listed as being positive (documented continued use, wellbeing, and physiological stability) or negative (refusal to continue using non-invasive ventilation). Discomfort or inconvenience to the patient because of the ventilator were included as negative outcomes. Outcomes were documented by follow up at the clinic or, in the case of patients who came to the clinic less than once a year, by telephone. Some patients continued to use their ventilators despite reporting certain discomforts. The number of respiratory events requiring admission to hospital before and after starting non-invasive ventilation were also documented.

\section{STATISTICAL METHODS}

Comparisons were conducted between pretreatment and the most recent physiological variables while the patients were receiving non-invasive ventilatory assistance for the two largest groups-namely, patients with poliomyelitis and Duchenne's muscular dystrophy. Because an initial check of the underlying distributions revealed a significant skewness for most of the outcome variables, non-parametric statistical procedures were used to test group differences. ${ }^{8}$ For each of the parameters investigated the Wilcoxon rank sum test was used to assess differences in central tendency between pretreatment and the most recent measurements. The tests were two tailed and were conducted at the 0.05 level of significance.

\section{Results}

Tables 2 and 3 summarise the demographic and physiological features, duration of treatment, and numbers of patients who received tracheostomies or died while on negative or positive pressure ventilation. Forty two (58\%) of the 73 patients with neuromuscular disease used M/NIPPV while 31 (42\%) used body ventilation (tank or cuirass). The six patients with chest wall disorders were ventilated by NIPPV exclusively.

NEGATIVE PRESSURE VENTILATION

As can be seen from table 2, 25 patients ( $81 \%$ ) using tanks or shells consisted of those with poliomyelitis. Sixteen (64\%) of these 25 patients were placed on negative pressure ventilation at the onset of their illness at a mean (SD) age of 25.1 (9.3) years. The other nine patients with poliomyelitis required ventilation later as a result of post-poliomyelitis syndrome. The fact that the group who received body 


\begin{tabular}{|c|c|c|c|c|c|c|}
\hline \multirow[b]{2}{*}{ Type of ventilation/diagnosis } & \multicolumn{6}{|l|}{ Reasons } \\
\hline & $\begin{array}{l}\text { Progression of disease and hypoventilation unable } \\
\text { to be controlled by non-invasive ventilation }\end{array}$ & $\begin{array}{l}\text { Uncontrollable } \\
\text { secretions }\end{array}$ & Pneumonia & $\begin{array}{l}\text { Total of } \\
\text { indications }\end{array}$ & $\begin{array}{l}\mathrm{PCO}_{2} \\
(\mathrm{~mm} \mathrm{Hg})\end{array}$ & FVC $(l ; \%$ predicted $)$ \\
\hline \multicolumn{7}{|l|}{ Negative pressure } \\
\hline Poliomyelitis & $10 \dagger$ & 3 & 1 & $14 \dagger$ & $55.7(13.8)$ & 746 (330); $18(8) \%$ \\
\hline Non-Duchenne's myopathy & 2 & - & - & 2 & $68.5(10.5)$ & $550(350) ; 14(10) \%$ \\
\hline Motor neurone disease & 1 & - & - & 1 & 53 & $300 ; 9 \%$ \\
\hline \multicolumn{7}{|c|}{ Mouth/nasal intermittent positive pressure (M/NIPPV) } \\
\hline Poliomyelitis & 1 & - & - & 1 & 69 & $1100 ; 31 \%$ \\
\hline Duchenne's muscular dystrophy & 5 & 3 & 2 & 10 & $46.6(10.3)$ & 490 (353); $10(6) \%$ \\
\hline Other myopathy & 1 & - & - & 1 & 54 & $500 ; 11 \%$ \\
\hline
\end{tabular}

Values are mean (SD) unless otherwise stated.

$\mathrm{PCO}_{2}=$ carbon dioxide tension; $\mathrm{FVC}=$ forced vital capacity.

†Significantly different from polio-M/NIPPV group, $\mathrm{p}<0.05$ (Wilcoxon rank sum test).

ventilation was younger than those who received M/NIPPV contributed to the longer duration of ventilation (24 versus 3.2 years, $\mathrm{p}<0.01$ ). While on body ventilation the poliomyelitis patients experienced a $9 \%$ decrease in their FVC, an annual decrease of $4.8 \mathrm{ml} /$ year which was not statistically significant. $\mathrm{PCO}_{2}$ also did not change significantly, remaining at $46 \mathrm{~mm} \mathrm{Hg}$.

Fourteen patients with poliomyelitis (56\%) eventually received tracheostomies for positive pressure ventilation, 10 for progressive hypoventilation (mean (SD) $\mathrm{PCO}_{2} 65(8) \mathrm{mm} \mathrm{Hg}$ ) which could not be corrected by any ventilatory aid and four with secretions (one with pneumonia) who were unable to be managed with manual coughing techniques or an exsufflation-insufflation device (available to one fifth of poliomyelitis patients; table 4). There were six deaths in this subgroup (table 2); the reported causes were pneumonia (two), myocardial infarction (two, one complicated by ventricular arrhythmia), intractable congestive heart failure related to ischaemic heart disease (one), and accidental tracheostomy disconnection at home (one).

Of the remaining six patients who received negative pressure ventilation, five received ventilator support for shorter periods of time (mean 8.2 years). The exception was a 47 year old woman with multiple sclerosis who received shell ventilation at night for 33 years (table 2). All six patients used shells, with two patients with spinal muscular atrophy supplementing it with daytime mouth positive ventilation. All patients in this group had variable degrees of decline in FVC, the most severe decrease being observed in the two patients with nonDuchenne's myopathies. Both patients eventually required tracheostomies because of progressive hypoventilation (33\% increase in $\mathrm{PCO}_{2}$ ) which also could not be managed by M/NIPPV. Three non-poliomyelitis patients receiving negative pressure ventilation died at home. The cause of death in two patients with motor neurone disease (amyotrophic lateral sclerosis) was pneumonia in one and was not known in the second (spinal muscular atrophy). The third patient with multiple sclerosis succumbed to a cerebrovascular accident.

MOUTH/NASAL POSITIVE VENTILATION

Again the largest group of patients who received this type of ventilator assistance comprised $20(42 \%)$ with poliomyelitis (table 3$)$.
They were placed on N/MIPPV more recently and therefore used it for a shorter time than those who received negative pressure ventilation (mean 3.2 versus 24.2 years, $\mathrm{p}<0.01$ ), reflecting the increased use of N/MIPPV in recent years. Their FVC and $\mathrm{PCO}_{2}$ values were, respectively, $42 \%(\mathrm{p}<0.01)$ and $12 \%(\mathrm{p}<0.05)$ higher. Compared with poliomyelitis patients receiving body ventilation they had a modest increase in FVC (8\%, not significant) and decline in $\mathrm{PCO}_{2}(15 \%, \mathrm{p}<0.05)$. On average their FVC increased at a rate of $90 \mathrm{ml} /$ year $(3.6 \%$ predicted/year) but the variability in change was quite high (coefficient of variation $40 \%$ ), partly because of the differing lengths of time on ventilation. Only one of these patients required a tracheostomy, a 63 year old man who had been using mouth positive ventilation at night and for most of the day for 12 years and had experienced increasing frequency of respiratory infections and retained secretions not eliminated by manual coughing techniques. Thus, the difference in the number of patients eventually receiving tracheostomies between the body and positive pressure ventilation groups was fairly high $(56 \%$ versus $5 \%$, $\mathrm{p}<0.001)$.

Fifteen patients (31\%) had Duchenne's muscular dystrophy. They were initially evaluated and recruited at a special clinic for patients with Duchenne's muscular dystrophy undergoing assessment for medical and psychosocial needs. ${ }^{9}$ Ten (67\%) eventually received tracheostomies. At the time their mean FVC and $\mathrm{PCO}_{2}$ were $530 \mathrm{ml}$ and $46 \mathrm{~mm} \mathrm{Hg}$. All complained of increasing orthopnoea and restlessness, particularly at night, which prevented sleep, and increasing bulbar difficulties and aspiration which could not be cleared with manual coughing techniques or prevented by a gastrostomy or jejunostomy feeding tube. Two of the 10 patients required multiple admissions to hospital for pneumonia while on NIPPV which directly contributed to the need for a tracheostomy (table 4). One patient with Duchenne's muscular dystrophy whose FVC declined to an unmeasurable value over five years was adamantly opposed to a tracheostomy and was able to sustain himself using a face mask/IPPV device 24 hours a day.

Of the remaining seven patients with neuromuscular disease, one with a non-Duchenne's myopathy developed a further decline in his respiratory function and an inability to main- 
Table 5 Patient outcomes

\begin{tabular}{|c|c|c|c|c|c|c|}
\hline \multirow[b]{2}{*}{ Ventilation/diagnosis (n) } & \multirow[b]{2}{*}{ Positive } & \multicolumn{5}{|l|}{ Negative } \\
\hline & & Tracheostomy & Death & $T+D$ & $\begin{array}{l}\text { Machine/interface } \\
\text { intolerance }\end{array}$ & $\begin{array}{l}\text { Discontinued by } \\
\text { patient on own }\end{array}$ \\
\hline \multicolumn{7}{|l|}{ Body ventilation (31) } \\
\hline Poliomyelitis (25) & 8 & 10 & 2 & 4 & 2 & 1 \\
\hline Non-DMD (2) & - & 2 & - & - & - & - \\
\hline MND (2) & - & - & 1 & 1 & - & - \\
\hline Diaphragmatic paralysis (1) & 1 & - & - & - & - & - \\
\hline Multiple sclerosis (1) & - & - & 1 & - & 1 & - \\
\hline No. total outcomes (\%) & $9(29)$ & $12(39)$ & $4(13)$ & $5(16)$ & $3(10)$ & $1(0.3)$ \\
\hline \multicolumn{7}{|l|}{ M/NIPPV (48) } \\
\hline Poliomyelitis (20) & $18 \dagger$ & 1 & - & - & 3 & 1 \\
\hline $\operatorname{DMD}(15)$ & 5 & 9 & - & 1 & 4 & - \\
\hline Other myopathies (2) & 1 & 1 & - & - & 1 & - \\
\hline MND (2) & 1 & - & 1 & - & - & - \\
\hline Peripheral neuropathy (1) & 1 & - & - & - & - & 1 \\
\hline Multiple sclerosis (2) & - & - & - & - & 2 & 2 \\
\hline Kyphoscoliosis (5) & 5 & - & - & - & - & - \\
\hline TB thoracoplasty (1) & 1 & - & - & - & - & - \\
\hline No. total outcomes (\%) & $32(67)$ & $11(23)$ & $1(2)$ & $1(2)$ & $10(21)$ & $4(8)$ \\
\hline
\end{tabular}

Values are mean (SD) unless otherwise stated.

$\mathrm{DMD}=$ Duchenne's muscular dystrophy; non-DMD = non-Duchenne's myopathy; $\mathrm{MND}=$ motor neurone disease $\mathrm{T}+\mathrm{D}=$ tracheostomy followed by death.

Note that some patients may have more than one outcome.

$\dagger$ Difference between polio-body ventilation and polio-M/NIPPV significant, $\mathrm{p}<0.01$ (Wilcoxon rank sum test).

tain a tight seal regardless of the type of nasal/ facial interface used because of insufficient family support at home; after two years he eventually received a tracheostomy to maintain 24 hour home ventilation. The six patients with chest wall disorders were maintained on nocturnal NIPPV for an average of 2.5 years. Overall lung function did not change significantly over this time, although the $\mathrm{PCO}_{2}$ did decrease by $28 \%$ in the patient with thoracoplasty.

Two patients receiving NIPPV died during this period. One was a 59 year old woman with amyotrophic lateral sclerosis who developed severe bulbar weakness and was reported to have succumbed to pneumonia at home. The second patient was a 23 year old man with Duchenne's muscular dystrophy who died of pneumonia and cardiomyopathy.

PATIENT OUTCOMES

Table 5 expands on the outcomes of all patients. It can be seen that tracheostomy did not prevent death in four patients (three of

Table 6 Hospital admissions before and after initiation of non-invasive ventilation

\begin{tabular}{lll}
\hline & \multicolumn{2}{l}{$\begin{array}{l}\text { No. of hospital } \\
\text { admissions/patient years }\end{array}$} \\
\cline { 2 - 3 } Type of ventilation/diagnosis (n) & Pre-NIV & Post-NIV \\
\hline Negative pressure & & \\
$\quad$ Poliomyelitis (25) & $5 / 606 \ddagger$ & $39 / 606+\ddagger$ \\
Non-Duchenne's myopathy (2) & $0 / 8.3$ & $0 / 8.3$ \\
Motor neurone disease (2) & $1 / 46$ & $0 / 46$ \\
Diaphragmatic paralysis (1) & $0 / 11$ & $0 / 11$ \\
Multiple sclerosis (1) & $0 / 2.8$ & $0 / 2.8$ \\
N/MIPPV & & \\
Poliomyelitis (20) & $4 / 66$ & $1 / 66$ \\
Duchenne's muscular dystrophy (15) & $7 / 30$ & $6 / 30$ \\
Other myopathies (2) & $0 / 8.3$ & $0 / 8.3$ \\
Motor neurone disease (2) & $0 / 9.7$ & $0 / 9.7$ \\
Peripheral neuropathy (1) & $0 / 0.4$ & $0 / 0.4$ \\
Multiple sclerosis (2) & $0 / 2.8$ & $0 / 2.8$ \\
Kyphoscoliosis (5) & $0 / 12.6$ & $0 / 12.6$ \\
S/P lobectomy/thoracoplasty (1) & $0 / 2.7$ & $0 / 2.7$ \\
\hline
\end{tabular}

NIV = non-invasive ventilation

†Significantly different from pre-NIV hospital admissions, $\mathrm{p}<0.01$ (paired $t$ test).

$\ddagger$ Significantly different from corresponding M/NIPPV-polio group, $\mathrm{p}<0.01$ (Wilcoxon rank sum test). whom succumbed to cardiovascular events). Three patients on shells complained of chafing and skin pressure changes. In the M/NIPPV group, in which there were only two deaths, 10 patients complained of nasal/facial interface discomfort. Four of these decided that they were not getting enough benefit from their machines and discontinued using them. Conversely, 18 patients continued to use their devices despite inconveniences. Most described decreased fatigue, breathlessness, and daytime drowsiness - that is, sufficient improvement to overcome the discomforts. Overall, a proportionally greater number of patients on M/NIPPV reported a positive outcomethat is, an improved sense of wellbeing and independence - than did those receiving body ventilation $(67 \%$ versus $29 \%, \mathrm{p}<0.01)$. None of the six patients with chest wall disorders (all on NIPPV) required tracheostomies, and all reported an improved sense of wellbeing, decreased feeling of tiredness, and increased activity throughout the day.

HOSPITAL ADMISSIONS

Table 6 summarises the number of hospital admissions for respiratory complications categorised by the type of non-invasive ventilation. In the 674 patient years from the first hospital admission for respiratory impairment to the onset of negative pressure ventilation 31 patients were admitted to hospital a total of five times (0.007 times per year) compared with 39 times during the subsequent 674 patient years (0.058 times per year) on ventilation, representing an eightfold increase $(p<0.01)$. In contrast, in the 48 patients who received M/NIPPV the overall rate of hospital admissions decreased from 11 to seven admissions per 133 patient years (from 0.083 to 0.053 times per year) which was not significant. Patients were supported by body ventilation for five times as many patient years as were those who received $\mathrm{M} / \mathrm{NIPPV}$ despite the fact that there were 18 more patients in the latter group. This difference was mostly because some poliomy- 
elitis patients had been ventilated in iron lungs and cuirasses for 30 years or more.

\section{Discussion}

The key findings of this study are as follows:

(1) While many patients (mostly those with poliomyelitis) were able to maintain ventilator support with negative pressure devices in the community, respiratory complications with this mode were commonly encountered. Patients in this group with bulbar difficulties with resulting aspiration and pneumonia had, in many cases, deteriorating ventilator function. Ultimately, 14 of 25 patients with poliomyelitis $(56 \%)$ on iron lung or cuirass ventilation received tracheostomies. By contrast, only one of 20 patients with poliomyelitis on $\mathrm{M} / \mathrm{NIPPV}$ required a tracheostomy, although this group has been followed for a much shorter period of time.

(2) Two thirds of patients with Duchenne's muscular dystrophy (the second largest group studied) ultimately required tracheostomies for various reasons, mostly related to a progressive decline in respiratory and bulbar muscle function.

(3) All six patients with chest wall disorders (five with kyphoscoliosis, one with posttuberculosis surgery) tolerated NIPPV well and remained on the treatment for the duration of the study.

(4) The hospital admission rate increased by nearly eight times in patients receiving negative pressure ventilation (all with poliomyelitis), while there was no increase in hospital admissions (in fact, a modest decline) in those who received M/NIPPV. The use of NIPPV in patients with Duchenne's muscular dystrophy did not significantly reduce hospital admissions.

(5) Most deaths occurred in the poliomyelitis patients who received negative pressure ventilation, but the causes were varied and not necessarily directly related to respiratory complications.

NEUROMUSCULAR DISEASES

In 1957 Affeldt et $a l^{2}$ reported functional recovery in 500 poliomyelitis patients with respiratory insufficiency in Los Angeles County who were admitted to Rancho Los Amigos for further care and rehabilitation. Four to seven years after the onset of their condition $10 \%$ of these patients were still using respiratory support while $73 \%$ were completely free of respirators. There is evidence that overuse of remaining muscles leads to delayed loss of function, including respiratory muscles. ${ }^{10-12}$ Twenty of our 45 patients (44\%) with poliomyelitis had late onset respiratory insufficiency. Of the 25 patients who required respiratory assistance from the time of their acute illness or soon after, all but one received cuirass ventilation; 14 of these have since required tracheostomies. The main reasons for switching to tracheostomy assisted ventilation were progressive loss of respiratory muscle reserve, inability to handle airways secretions, or an acute respiratory event (pneumonia, atelectasis, pneumot- horax). Patients generally used respiratory aids at night with some periods during the day (2-8 hours), but those with a VC of $<10 \%$ predicted were unable to tolerate spontaneous ventilation for more than 15 minutes. These findings are similar to the experience of Bach et $a l^{13}{ }^{14}$ who found almost no tolerance off ventilation in patients with a VC $<12 \%$ predicted.

During acute episodes of respiratory infection or airway congestion most patients increased their time on ventilation during the daytime to reduce dyspnoea and to maintain their tolerance for independent activities. Mobilisation of secretions was facilitated through the use of vigorous chest percussion, postural drainage, and assisted coughing techniques. A mechanical insufflation-exsufflation device was used by $20 \%$ of our poliomyelitis patients to provide effective pulmonary toilet. ${ }^{15}$ Glossopharyngeal breathing was employed by one third of our patients during the day to augment their breathing and speech and to "stretch their lungs".

For patients with neuromuscular respiratory muscle dysfunction the expiratory muscles are frequently of concern. Such patients have weaker expiratory muscles than inspiratory muscles, resulting in an ineffective cough. ${ }^{16}$ These patients are usually asymptomatic until an upper respiratory tract infection leads to increasing respiratory distress, hypoxaemia, hypercapnia, intubation for ventilatory support and airway suctioning and, eventually, when airway secretions cannot be cleared, to tracheostomy. ${ }^{16-18}$ Some of our patients with poliomyelitis had long term access to mechanical insufflation-exsufflation devices while others did not (since the machine came back on the market in 1993). Thus, it is possible that some patients who required tracheostomies did so in view of the lack of uniform access to such devices. Nevertheless, all of our poliomyelitis patients were originally trained in the use of glossopharyngeal breathing (although not all used it), and all patients with neuromuscular and chest wall disorders and their home caregivers were trained in the proper use of manually assisted coughing techniques. Follow up interviews with the patients and their caregivers noted that virtually all patients were still knowledgeable in the use of such manoeuvres long after recovery from their initial illness. The fact that $37 \%$ of patients with neuromuscular disorders still received tracheostomies is an indication of the progressive decline in respiratory and bulbar function. Nearly $75 \%$ of these patients experienced worsening hypoventilation which could not be prevented despite the use of manual coughing techniques, periodic sighs by M/NIPPV, or the exsufflation-insufflation device available to some patients. Body ventilation can be effective but it has many inconveniences and can promote upper airway collapse and aspiration of secretions leading to respiratory complications. ${ }^{19-21}$ Body ventilators also become less effective as lung volumes and compliance decrease with aging or progressive disease (as can occur with poliomyelitis and myopathies). ${ }^{4}$ Most of our patients $(76 \%)$ on 
negative pressure ventilation who required tracheostomies did so because of progression of disease and hypoventilation (table 4).

The decline in FVC in our patients with Duchenne's muscular dystrophy $(60 \mathrm{ml} /$ year or $2.3 \%$ per year) is similar to the overall declines described by others (4-5\% per year)..$^{22-25}$ Newsom-Davis et al $l^{6}$ showed no clear relationship between the tendency to hypoventilate and the overall degree of respiratory muscle weakness as judged by the vital capacity. We also failed to find a significant (inverse) correlation between FVC (\% predicted) and $\mathrm{PCO}_{2}$ (Pearson correlation coefficient, $r=0.15$, NS).

Our experience has been similar to that of Leger $e t a l^{7}$ who had to provide tracheostomies for $31 \%$ of their patients with Duchenne's muscular dystrophy for reasons including abdominal bloating and distension during NIPPV, anxiety, and uncontrollable hypercapnia related to progressive disease. By contrast, our experience differed from that of $\mathrm{Bach}^{16-18}$ who stated that tracheostomy should be considered exclusively for bulbar dysfunction, implying that none or few of his patients exhibited this problem to a significant degree. In fact we have found that, after a period of 1-2 years on NIPPV, many of our patients began to experience increasing swallowing difficulties. Despite instructions to the family regarding chest drainage and percussion, manual coughing and positioning, and the placement of gastrostromies or jejunostomies, recurrent aspirations have been unavoidable. Yet two patients with Duchenne's muscular dystrophy have been able to stay on NIPPV virtually all day because of their refusal to accept tracheostomies and currently remain free of respiratory complications. These findings are in line with Bach's studies which describe 24 hour maintenance of patients with no measurable VC. ${ }^{16-18}$

\section{CHEST WALL DISORDERS}

In patients with chest wall disorders there is a relation between the extent of respiratory muscle weakness and degree of hypercapnia, but other factors such as the degree of thoracic spinal curvature, alteration of the mechanical properties of the respiratory system, and the central control of respiration all contribute. ${ }^{28}$ Generally, thoracic curvatures of 100 degrees or greater are associated with an increased likelihood of respiratory failure. ${ }^{29}{ }^{30}$ If left untreated, $50 \%$ of patients who develop respiratory failure die within one year. ${ }^{31}$ With appropriate management, however, median survival can be as long as nine years. ${ }^{29}$ All six of our patients described decreased exertional dyspnoea, more energy, and increased ability to conduct daily activities despite no overall change in the $\mathrm{VC}$ or $\mathrm{PCO}_{2}$ (table 1). These findings are similar to those described by Hoeppner and colleagues ${ }^{30}$ in four hypercapnic individuals with kyphoscoliosis who were treated with tracheostomy assisted ventilation for a mean of 3.4 years.

MOTOR NEURONE DISEASE

The two patients with motor neurone disease who received negative pressure ventilation did not fare as well as the two who received $\mathrm{M} / \mathrm{NIPPV}$, despite the fact that those receiving negative pressure ventilation had an initial VC $55 \%$ higher than those receiving M/NIPPV. The patients in the negative pressure ventilation group experienced a $68 \%$ decline in VC (25 ml per year decline) while those receiving $\mathrm{M} / \mathrm{NIPPV}$ had a $39 \%$ increase in VC $(104 \mathrm{ml}$ per year gain). Those receiving body ventilation were nearly 20 years older, possibly accounting for their decline in respiratory function. This experience is similar to those of others who also found that M/NIPPV results in fewer respiratory complications than body ventilation, and is more comfortable, feasible, and efficient. ${ }^{32}{ }^{33}$ The one patient in the group who remains alive uses a mouth seal for 8-10 hours at night and as needed during the day. Bach and $\mathrm{Alba}^{34}$ have reported the safety and effectiveness of mouth seal ventilation in patients with postpoliomyelitis syndrome and traumatic high level quadriplegia.

The data reported in this study must be assessed with caution, and there are some limitations. The retrospective design, different teams and equipment involved in the management over the years, improved technology of monitoring and ventilator equipment, especially during the last two decades, and the heterogeneity in size of the different patient groups involved could all influence the results. For example, only $20 \%$ of patients on body ventilators (all with poliomyelitis) had access to exsufflation-insufflation devices long term. The machine has been back on the market only since 1993. Thus, it is possible that some patients who received tracheostomies did so because of lack of uniform access to this and other assisted coughing devices. Knowing that non-invasive IPPV is more effective than negative pressure ventilator use, with the description of nasal IPPV in 1987 and with currently available technologies to eliminate airway secretions, what was true in 1949 is not true today. As shown above, the most important comparisons were made between the largest groups-namely, those with poliomyelitis (negative versus positive pressure ventilation) and Duchenne's muscular dystrophy. Ultimately, the respiratory problems of these patients were managed by medical and allied health staff who were trained and worked in the same setting for many years and, in some instances, over many decades.

In summary, our lengthy experience with non-invasive ventilation has shown a generally satisfactory outcome in patients with neuromuscular and chest wall disorders, with patients with poliomyelitis receiving the longest ventilator support with negative pressure devices. Overall, $37 \%$ of the patients required tracheostomies, the majority because of progression of disease and inability to prevent or reverse hypoventilation despite the use of various ventilator/airway interfaces; a smaller number needed a tracheostomy because of uncontrollable secretions and recurrent aspiration despite the use of manual coughing techniques and the exsufflation-insufflation device. Most of the deaths (90\%) occurred in 
patients supported by body ventilators, confirming previous experience on the greater feasibility, safety, and acceptance of positive pressure devices by patients with such conditions. Patients with neuromuscular and chest wall disorders who received M/NIPPV have, in general, done better with little or no deterioration of respiratory function and no increased need for admission to hospital.

The authors wish to thank the following for their assistance: $\mathrm{Mr}$ Jerry Valencia, Mr Ronald Rose, $\mathrm{Mr}$ Michael Rudolph, and Ms Clementine Brown for obtaining the pulmonary function and blood gas data; members of the medical, nursing, respiratory therapy and allied health departments at Rancho Los Amigos Medical Center whose dedication and work have enabled its patients to lead lives to the fullest potential and independence;
and Carolina De La Cruz (USC) and Minerva Castillo (USC) in the preparation of this manuscript.

1 Petty TL. A historical perspective of mechanical ventilation. In: Tobin MJ, ed. Mechanical ventilation. Crit Care Clin 1990;6:489-504

2 Affeldt JE, Bower AG, Dail CW. The prognosis for respiratory recovery in severe poliomyelitis. Arch Phys Med Rehabil 1957;38:383-8.

3 Knaus WA. Prognosis with mechanical ventilation: the influence of disease, severity of disease, age, and chronic health status on survival from an acute illness. Am Rev Respir Dis 1989;140(Suppl):S8-13.

4 Make BJ. Mechanical ventilation beyond the intensive care unit. Report of a consensus conference of the American College of Chest Physicians. Chest 1998;113(Suppl):289College

5 Morris JF, Koski A, Johnson LC. Spirometric standards for healthy, nonsmoking adults. Am Rev Respir Dis 1971;103: 57-67.

6 Hepper NGG, Black LF, Fowler WS. Relationship of lung volume to height and arm span in normal subjects and in patients with spinal deformity. Am Rev Respir Dis 1965;91: 356-62.

7 Hackney JD, Spears CH, Collier CR. Estimation of arterial $\mathrm{CO}_{2}$ tension by rebreathing technique. $\mathcal{F}$ Appl Physiol 1958; 12:425-30.

8 Hays WL. Statistics. 3rd ed. New York: Holt, Rinehart and Winston, 1981

9 Gilgoff I, Prentice W, Baydur A. Patient and family participation in the management of respiratory failure in Duchenne's muscular dystrophy. Chest 1989;95:519-24.

10 Fischer DA. Poliomyelitis: late respiratory complications and management. Orthopedics 1985;8:891-4.

11 Hamilton EA, Nichols PJR, Tait GBW. Late onset of respiratory insufficiency after poliomyelitis. Ann Phys Med ratory insufficienc.

12 Lane DJ, Hazleman B, Nichols PJR. Late onset respiratory failure in patients with previous poliomyelitis. $O \mathcal{F} \mathrm{Med}$ failure in patients

13 Bach JR, Alba AS. Non-invasive options for ventilator support of the traumatic high level quadriplegic. Chest 1990;98:613-9.
14 Bach JR, Alba AS, Shin D. Management alternative for post polio respiratory insufficiency: assisted ventilation by nasal or oral-nasal interface. Am f Phys Med Rehabil 1989;68: 264-71.

15 Bach JR. Mechanical insufflation exsufflation. Comparison of peak expiratory flows with manually assisted and unassisted coughing techniques. Chest 1993;104:1553-62.

16 Bach JR. The prevention of ventilatory failure due to inadequate pump function. Respir Care 1997;42:403-13.

17 Bach JR. You need more than nocturnal NIPPV to manage Duchenne's muscular dystrophy. Chest 1995;107:592.

18 Bach JR. Amyotrophic lateral sclerosis: communication status and survival with ventilatory support. Am F Phys Med Rehabil 1993;72:343-9.

19 Hill NS. Clinical application of body ventilators. Chest 1986;90:897-905.

20 Splaingard ML, Frates RC, Jefferson LS, et al. Home negative pressure ventilation: report of 20 years of experience in patients with neuromuscular disease. Arch Phys Med Rehabil 1985;66:239-42.

21 Bach JR, Penek J. Obstructive sleep apnea complicating negative pressure ventilatory support in patients with chronic paralytic/restrictive ventilatory dysfunction. Chest 1991;99:1386-93.

22 Baydur A, Gilgoff I, Prentice W, et al. Decline in respiratory function and experience with long-term assisted ventilation in advanced Duchenne's muscular dystrophy. Chest 1990; in advanced

23 Kurz LT, Mubarak SJ, Schultz P, et al. Correlation of scoliois and pulmonary function in Duchenne muscular dystrophy. F Pediatr Orthop 1983;3:347-53.

24 Jenkins JG, Bohn D, Edmonds JF, et al. Evaluation of pulmonary function in muscular dystrophy patients requiring spinal surgery. Crit Care Med 1982;10:645-9.

25 Rideau Y, Janoski LW, Grellet J. Respiratory function in the muscular dystrophies. Muscle Nerve 1981;4:155-64

26 Newsom-Davis J, Loh L. Alveolar hypoventilation and respiratory muscle weakness. Bull Eur Physiopathol Respir 1979;15:45-51.

27 Leger P, Bedican JM, Cornette A, et al. Nasal intermittent positive pressure ventilation. Long-term follow-up in patients with severe chronic respiratory insufficiency. Chest 1994;105:100-5.

28 Bergofsky E. Thoracic deformities. In: The Thorax. Part C. Disease. Lung Biology in Health and Disease. Vol 85. New Disease. Lung Biology in Health and Dise

29 Libby DM, Briscoe WA, Boyce B, et al. Acute respiratory failure in scoliosis or kyphosis. Prolonged survival and treatment. Am F Med 1982;73:532-8.

30 Hoeppner VH, Cockcroft DW, Dosman JA, et al. Nightime ventilation improves respiratory failure in secondary kyphoscoliosis. Am Rev Respir Dis 1984;129:240-3.

31 Bergofsky EH, Turino GM, Fishman AP. Cardiorespiratory failure in kyphoscoliosis. Medicine 1959;38:263-317.

32 Rodenstein DO, Stanescu DC, Delguste P, et al. Adaptation to intermittent positive pressure ventilation applied through the nose during day and night. Eur Respir f 1989; 2:473-8.

33 Zibrak JD, Hill NS, Federman EC, et al. Evaluation of intermittent long-term negative-pressure ventilation in patients with severe chronic obstructive pulmonary disease. Am Rev Respir Dis 1988;138:1515-8.

34 Bach JR, Alba AS. Non-invasive options for ventilatory support of the traumatic high level quadriplegic patient. Chest 1990;98:613-9. 